Gynec. Invest. 1972;3:250-252

\title{
Announcements
}

Adenocarcinoma Registry

Clear-cell adenocarcinomas of the genital tract (mesonephroma) in young women have recently been associated with maternal stilbestrol administration [N. Engl. J. Med. 284: 878, 1971;

Cancer 25: 745, 1970]. Since the experience of any one clinic with these tumors will be small, a Registry supported by grants from the American Cancer Society and the National Institutes of Health has been established to centralize data and to study pathogenesis, maternal histories and therapy from cases in the United States and abroad.

Confidentiality will be strictly maintained. No patient will be identified in any information or report released from the Registry. Data is sought on all cases including those to be published by the reporting physician or institution. Specific permission will be obtained to include the information from each case in any reports emanating from the Registry.

We seek information on all cases of clear-cell adenocarcinoma of the genital tract in women under age 25 years whether or not there is a history of maternal hormone ingestion. Please direct all communications to: Registry of Clear-Cell Adenocarcinoma (Mesonephroma) of the Genital Tract in Young Women, Warren 275, 275 Charles Street, Boston, MA 02114 (USA)

A.L. Herbst, Director R.E. Scully, Pathologist

Planned Parenthood Association Chicago Area

We all recognize the worldwide need for an immediate and massive expansion in trained workers in family planning. This surely needs no elaboration.

Planned Parenthood Association - Chicago Area, under a contract with the Agency for International Development, offers a system of comprehensive training programs in the procedures and methods of effective family planning. These programs are suitable for either groups or individual trainees, and are constructed to focus on the specific needs of program participants. Planned Parenthood Association brings to this effort 25 years of experience in family planning and population control: experience and contacts with doctors, nurses, midwives, communicators, administrators, health educators, social workers, and general educators; from Chicago, from the United States, and from many countries around the globe.

The result has been a system of training programs characterized by great flexibility and a wide range of available expertise.

For eligibility determination, contact may be made with local AID missions or other organizations offering grants or fellowships to qualified foreign nationals.

Announcements

251

For this vital program to receive greatest possible exposure, your cooperation is requested in the area of direct referrals and the sharing of this information with your many constituents and contacts involved in family planning.

Address: Planned Parenthood Association - Chicago Area, 185 North Wabash Avenue, Chicago, IL 60601 (USA)

6th Postgraduate Course 


\section{Offered by}

the American Fertility Society

The 6th postgraduate course to be offered by the American Fertility Society will be given at the Hilton Hotel, San Francisco, Calif., on Wednesday, April 4, 1973, preceding the 29th annual scientific meeting of the society. The schedule will include sessions on endoscopy, surgery and infertility, artificial insemination, endocrinology, male infertility including urologic factors, office management of the infertile couple, and basic reproductive mechanisms as related to clinical infertility problems.

Sessions will be limited. The registration fee will be $\$ 75.00$ per session. Details and registration applications may be obtained from Winfred L. Wiser, M.D., 1801 Ninth Ave. South, Birmingham, AL 35205.

International Congress on Immunology in Obstetrics and Gynaecology in Padua (Italy) 7-9 June, 1973

An International Congress on 'Immunology in Obstetrics and Gynaecology' will be arranged at Padua, Italy, on 7-9 June, 1973, under the auspices of CIOMS.

This congress intends to direct a spotlight on the existing relationship between immunology and obstetrics. A good number of outstanding Italian and foreign scientists have already given their agreement to send reports and reciprocal correspondence relevant to the themes to be treated. The congress will last 3 days, with two sessions per day. The following items will be discussed: 1st session: Male sterility on the basis of immunology 2nd session: Female sterility on the basis of immunology 3d session: Immunology of the conception product 4th session: Transplacentary passage of the anticorpse 5th session: Anticorpse antihormone 6th session: Immunology of gynaecological tumours

Information and subscriptions: Prof. Nicola Carretti, Obstetrics and Gynaecology Clinic of the University in Padua, Via Giustiniani 3, Padua 35100 (Italy)

252

Announcements

The Reinier de Graaf Tercentenary Symposium

will be held in Delft, The Netherlands, August 9-11, 1973; organized by the Society of Obstetrics and Gynaecology of the Netherlands.

Secretary: Prof. Dr. T.K.A.B. Eskes, St. Radboud Hospital, Nijmegen.

Lectures will be presented on several aspects of ovarian function.

A limited number of free communications can be accepted but should be submitted not later than April 1st, 1973. 